\title{
For the Definition of the Methodology of Nursing Education
}

H. Nikodemova (Hana Nikodemova)', L. Matulnikova (Ludmila Matulnikova)²

1 Charles University \& Motol University Hospital, Prague, CZ.

2 St. Elizabeth University of Health and Social Work in Bratislava, SK.

\section{E-mail address:}

hana.nikodemova@1fmotol.cuni.cz

\section{Reprint address:}

Hana Nikodemova

Department of Nursing, Second Faculty of Medicine, Charles University

V Uvalu 84

15006 Prague 5 - Motol

Czech Republic

Source: Clinical Social Work and Health Intervention

Pages: $70-78$

Volume: 10

Issue: 3

Cited references: 13

\section{Reviewers:}

Harald Stefan

Vienna General Hospital, Vienna, AT

Daniel J. West, Jr

University of Scranton, Department of Health Administration and Human Resources, USA

\section{Key words:}

Mentor of Clinical Practice. Certified Course. Competence. Educational outcomes. Practical Education in Nursing. Nursing.

\section{Publisher:}

International Society of Applied Preventive Medicine i-gap

CSWHI 2019; 10(2): 70 - 78; DOI 10.22359/cswhi_10_3_11 @ 2019 Clinical Social Work and Health Intervention

\section{Abstract:}

This paper addresses the competencies of clinical nursing educators that are necessary to form and develop the set of knowledge and skills key to successfully performing this role. For the purpose of this paper, attention is focused on the important link of competence assessment and teacher performance evaluation with the introduction of a qualification framework in tertiary education institutions, where educational outcomes are characteristically oriented towards the student. The fol- 
lowing is a presentation of our own quantitative research, which was carried out in the form of a self-evaluation questionnaire survey of 71 respondents - graduates of the certified course at the 2nd Faculty of Medicine and at the Motol University Hospital, and 38 respondents who completed the certified course in other accredited facilities. In terms of knowledge and skills, the self-evaluation of mentors has produced positive results. Mentors feel well prepared to perform their roles and apply the required knowledge and skills in practice. At the same time, there were differences discovered in the ability to implement certified courses that were supported by either a pedagogical mentoring model or a supportive mentoring model. This paper also includes selected results of the questionnaire survey, which can become an empirical basis for a wider debate on the concept of mentoring in the Czech Republic, and thus for the adjustment of relationships and competencies related to mentoring in nursing, as well as for further improvement of the educational programs of all types. The purpose of this paper is to point out the necessity of educational outcomes, which results from the considerable variability of certified courses.

\section{Introduction}

In the last 25 years, we have seen a number of changes throughout society that affect the nursing profession and its professional training. Currently, however, valid legislation requires that students be prepared to participate in the provision of specialized and highly specialized nursing care. A key task in the field of education is to educate a Nurse who is able to actively put theoretical and practical knowledge and skills into practice. It is also necessary to prepare graduates for postgraduate and lifelong education in health care.

The current model of practical nursing training, which largely consists of direct nursing apprenticeship by an educator who is the source of knowledge for students, is inadequate and ineffective because it is to a large extent limited by the ability of educators to reach the appropriate level of specified knowledge and skills in several clinical disciplines at the same time so that nursing practice can be carried out at the highest possible professional level, especially in faculty-type health care facilities where highly specialized diagnostic, treatment and nursing care is provided. The earlier model of practical training limits its content to basic nursing care; which is inadequate due to the current requirements for graduates of the qualification study; thus is essential that nurses with appropriate clinical specialization are provided with practical training. For nursing, it is also true, as stated by Matulnik (2009, p. 13), that: "Science is understood to mean: an institutionalized human activity aimed at the methodical creation of a system of new truthful knowledge, of individual realms of reality, which is expressed in specific terminology and whose purpose is to describe, explain and predict phenomena in given study areas. Theoretical scientific knowledge gained through cognitive activities and achievement through methodical work. It is a multidisciplinary subject with a theoretical basis and practical application." It is an integral part of the healthcare system, not only in the Czech Republic, but also around the world. 


\section{Custom text}

\section{Key Competencies of Mentors}

According to the academic dictionary of foreign words, the term competence refers to the assumptions (i.e. knowledge and skills) or the ability to handle a specific function, activity or situation. When formulating the intent of an educational program for the training of mentors of clinical nursing apprentices, we established the following general educational objectives:

- build, in nursing students, competence in the fields of pedagogy and psychology for the qualified performance of the mentoring position of clinical practice for nurses and midwives - for successful prognosis, implementation and evaluation of the educational process in the students' professional practice;

- Deepen the pedagogical and psychological thinking about the phenomena of educational reality for a deeper understanding of the causes, the course and consequences of pedagogical and life situations and for more qualified decision making in the educational field;

- Contribute to autonomy, creativity and flexibility in pedagogical work. Contribute to the integration of new theoretical knowledge with past experience in the field of practical teaching from the experience of those who participated as students.

With these goals in mind, we tried to specify the learned competencies of our course participants so that we can accurately develop the content of the individual educational units and subjects included in the certified course. In this context, we analysed not only available literature related to mentor competence (eg Ayfer and Hatice, 2008 or Jowett, 1994 and others). Literary analysis did not provide us with specific information about mentor competencies and their structure. For this reason, we used the basic structure of educator competencies, which is described in Průcha (Prucha, 1997) and we have modified and supplemented the individual areas of competence.

We also drew from current knowledge of the given problem which some authors point to of the important link between the assessment of competences and the assessment of performance of teachers. For example, Pabian (2012), highlighted in his study the direction of research on learning and educating in tertiary education forms the central concept of "educational approach". He believes that since its inception in the mid1970s, it has obviously become the most comprehensive and most important research area in the field, notably by giving straightforward key concepts, as well as sustained theoretical development from "educational approaches" to complex models of relationships between teaching to educate all the way to "educational outcomes." (Pabian, 2012, p. 48, 72)

According to Pabian, the area of education is defined primarily by descriptors illustrating educational outcomes that in a standardized form express the objectives of education and also reflect the common theoretical, methodological, philosophical and value basis of the given field of education. Educational descriptors translate loosely formulated descriptions of learning areas into the category of expected educational outcomes - knowledge, skills and other skills (competencies) of graduates, in accordance with national descriptors of the qualification framework.

It focuses on:

- Expertise in the given field (specification of factual and theoretical knowledge and level of understanding of the graduate of the main field); 
- Professional skills (specification of research, artistic or other practical practices applying the expertise of a given level).

(National Qualification Framework for Tertiary Education in the Czech Republic, 2012).

Recommendations on educational policy according to Hnilic and Pabian (2012), and therefore also the purpose of the national qualification framework, clearly describe the knowledge, skills, and general competencies that students acquire in individual programs/fields of study and tertiary education. The goal is to be transparent, clear, and understandable for all students. The National Qualification Framework is the starting point for the creation of study programs and majors at universities and educational fields. This framework focuses only on the learning outcomes of a particular curriculum, i.e. the expected knowledge, skills and competence of graduates. The National Qualification Framework is implemented mainly for the following reasons:

- Experience with the introduction of qualification framework in various countries shows that it contributes to focus on the content of education rather than meeting formal criteria and as a result leads to an improvement in the quality of studies.

These countries include the United Kingdom, Germany, the Netherlands, Norway, Denmark, Ireland, and non-European countries such as Australia, New Zealand, South Africa and Hong Kong;

- "on the basis of the obligations of the Czech Republic arising from the Bergen Communiqué of Ministers responsible for Higher Education (Commitment of the Bergen Communiqué requires the existence of the NKR and its "self-certification" over the overarching framework of qualifications for the European Higher Education Area - QF-EHEA) and from the Recommendations of the EU Counc of 23 April 2008 “. (Hnilica, Pabian, 2012, p. 18)

\section{Educational outcomes}

Educational outcomes represent a generic term for knowledge and skills, as well as general competencies that students have to acquire in a given field of study or subject. Every study branch and every one of its subjects have educational outcomes: that is what we expect students to learn during their studies. When we document these expectations we will acquire

a characteristic of the field and its subjects, which is extremely comprehensible to existing and potential students, as well as to employers. Students simply find out not only what they are they will learn during the course of their studies, but also what will know upon the completion of their degree - potential employers will know as well. This is the base reason why educational outcomes are also required for accreditation.

For Example: The Student Knows How:

- To explain the principles, methods and procedures of individual nursing activities to pediatric and adult patients;

- To respect the age, individual wishes and other peculiarities of clients/patients in providing nursing care;

- To perform nursing tasks for both pediatric and adult patients in standard and urgent care.

The educational outcomes express what a graduate of a study branch or a student can explain, evaluate, design, assemble etc. after completing the subject. During writing, we do not focus on what we do as an educator (our idea of what we are going to teach students), but what students and graduates will be able to do after graduation. 
A common problem is that we often write about something other than what a student or graduate should be able to do when they leave school:

For example:

The student will learn about the basic historical development of the field of study.

This formulation describes the course of the education, not the eventual output; it is necessary to re-formulate the statement, for example:

The student is able to characterize the three main historical stages in the development of the field of study.

With this stated output, it is clear to students what is expected of them in the final exam of the subject, and it is equally clear to new teachers, when they take over the lectures from someone else, what exactly to test, and we also write about knowledge and skills very generally: for example: The Student knows the principles of professional ethics.

The knowledge and skills of students, or the professional competencies of nurses, are divided into basic, specialized and highly specialized according to the basic functions that a general nurse performs and are based on current legislation in the Czech Republic.

\section{Objective of the empirical study:}

The aim of the empirical survey was; using an anonymous questionnaire to analyse the competencies of mentors in clinical nursing practice; focusing on the implementation of the individual stages of the educational process; to assess the extent to which the certified course for the preparation of mentors of clinical practice contributed to acquiring and deepening the knowledge and skills necessary for optimal practical training in the stated stages of the education process; to compare the results of self-evaluation of key competencies in CK graduates for the preparation of mentors from different health sectors with different accredited educational programs.

\section{Methodology}

The anonymous questionnaire of our own design was used to obtain the information necessary to achieve the objectives. During the design of the questionnaire, maximum attention was paid to the singular nature and clarity of each question. Through the questionnaire, the following information was collected from individual respondents:

- Information about the respondent

- A set of questions about planning and teaching

- A set of general questions

- A set of questions about the knowledge of the mentor

- A set of questions about other professional requirements

\section{Organization of the study}

The questionnaire survey was conducted at the end of the Summer Semester of the academic year 2013. The research was carried out in two stages. In the first phase, the questionnaire was assigned to mentors at the Second Medical Faculty of the Charles University in Motol, during January and February 2013. The first phase questionnaire was distributed in printed form to all 93 mentors/mentors. By the end of March 2013, 75 completed questionnaires were received. The return on questionnaires $(80.65 \%)$ was above expectations. After evaluating checkpoints in completed questionnaires, the three questionnaires were discarded for disbelief and one questionnaire was discarded due to the non-completion of all items. For the survey, a total of 71 questionnaires were used. Of the total number of mentors of the 2nd Medical Faculty of Charles University 
and Motol, 76.34\% participated in the survey. Participants in the first stage survey are the A group of respondents.

The second phase of the survey took place in September 2014. A total of 232 active mentors and mentors were contacted through accredited facilities (the Faculty of Health Studies at UWB in Plzeň, Regional Health, Shareholder Company Ústí nad Labem and the Faculty of Public Policy in Opava) and asked to fill in an electronic version of a questionnaire placed

on the website of the 2nd Faculty of Medicine in Prague. Of the total number of 232 mentors contacted, the questionnaire, even after several urgent reminders, was completed by only 46 respondents. The return rate was only $19.83 \%$.

\section{Characteristics of the respondent group}

The survey was completed by general nurses and midwives, performing mentorship activities in the conduct of clinical nursing practice for university students, who in the years 2012 - 2013 completed a certified training course for mentors in clinical nursing practice in one of the accredited facilities in the country. Based on the different types of training in the certified course, respondents were divided into two groups: Group A $(\mathrm{n}=71)$ consisted of interviewees who had special professional competence to pursue mentoring in the same courses, i.e. in courses at the Motol University Hospital or at the Second Medical Faculty of Charles University. The second Group B $(\mathrm{n}=38)$ consisted of respondents who have acquired special expertise in other accredited institutions (FZS UWB in Pilsen, FZV University of Ústí nad Labem and in FVP SU Opava).

\section{Selected results of the investigation}

A key part of our own research was analysis of the development of pedagogical and didactic competencies of mentors obtained through a certified course in relation to selected activities in the specific phases of practical training. From this analysis we can judge the effectiveness of the certified course because this analysis represents progress in the knowledge and skills of the mentors before the certified course and after passing it. The average values of the Gamma Correlation Coefficients are lower for the Group A respondents than for the B respondents. Thus, it can be concluded that the certified mentor training course developed the Group A respondent's knowledge and skills more than in the case of the B respondents. From this we can gather that all calculated values of the Gamma Correlation Coefficient are in the positive range, and it can be stated that the passing of the course, in any case positively influenced, more than less, the knowledge and skills of mentors, or at least did not deteriorate it (especially in group B). Although, in most cases, better results can be found in the presented results for Group A than B respondents, statistically significant differences were found for only two items and "I have sufficient knowledge of the educational program that is being carried out at the faculty" ( $\mathrm{p}=0,0208)$ and in the less significant item "I have the skills to orient in societal changes" ( $p=0.0168)$. In both these questions, better results were found for group A. In the group B respondents, slightly better results of self-evaluation on statements focusing on mentor behavior were found in practical training with a focus on access to and communication with students, for example on the statements:

- As a mentor, I lead students to a responsible approach to the profession; 
- As a mentor, I encourage and help to critical think about the profession;

- As a mentor, I behave as with a colleague, as a partner;

- As a mentor, I behave proactively;

- As a mentor, I effectively collaborate with the student and develop his or her interest in a particular skill;

- I believe that my student assessment strengthens, encourages, and motivates me towards further improvement and development.

\section{Discussion}

What is the Qualification Framework good for?

Recommendations for Educational Policy, according to Hnilic and Pabian, proposes defining the legal basis of the Qualification Framework; its binding nature; its forms; its management; possibilities for change; its guaranteeing its support.

The Education Policy Recommendation therefore seeks to systematically support the implementation and proper use of the Qualifications Framework at the highest level of universality. It is therefore clear that the main addressee of this recommendation is the Ministry of Education, Youth and Sports, which oversees and administers the Czech Educational System. However, even if the legal anchoring and management of a qualification framework at the national level is primarily addressed to the Ministry of Education, the Ministry of Education, Youth and Sports cannot proceed completely independently to other interest groups (particularly the Accreditation Commission and Academic Representation). For this reason, the recommendations for educational policy are of course also intended for tertiary education institutions and other bodies involved in the tertiary education process in the Czech Republic.
The other two recommendations are based primarily on the experience of pilot implementation of the national qualification framework and their end-users are primarily institutions of tertiary education, i.e. higher and upper vocational schools:

- Recommendations for school directors are formed from recommendations for tertiary education institutions when introducing Qualification Framework

- Educator recommendations deal with educational outcomes and help those who develop educational outcomes at the field of study and subject levels.

It should be stressed that both these recommendations, particularly for tertiary education institutions, are very closely interrelated. The School Leadership Recommendation is intended to help create an appropriate environment for the establishment of a Qualification Framework at the institutional level. Teacher recommendations should be a practical tool in making educational outcomes at the program, discipline, and subject level.

The general issue of Qualifications Frameworks is dealt with in the study of Allais, Raffe, Young, particularly the distinction between two types of Qualifications Frameworks: the first, the reform of education, and the second about the transparency of the existing education system. (Allais, Raffe, Young, 2009)

Undoubtedly, Bergan's study, a theoretical study on the problems of qualifications and Qualification Frameworks has made a major contribution to the topic, with particular emphasis on the importance of these issues in the area of European higher education. (Bergan, 2007). Furthermore, according to Chakroun it is important to note that the final conclusion, i.e. the framework and processes, its implementation, cannot be 
transferred to other countries; it is always necessary to create their own form of implementation. In addition, he argues that the pedagogical potential of educational outcomes can only be fully exploited in close conjunction with learning and evaluation. (Chakroun, 2010)

\section{Conclusion}

Past attempts at reform such as unifying mentor training in a single certified course are halfway solutions and the original goal is only partially fulfilled since it does not exactly define the educational outcomes, i.e. what a mentor of clinical practice should be familiar with and know, in that the portfolio, from which specific pedagogical - didactic competencies originate, to which this survey was devoted. The content analysis of the training programs of certified courses for mentor training carried out in 2010-2014 shows a great variability in content and extent of mentor preparation. The current "unified" curriculum issued by the Czech Ministry of Education while firmly defining the scope and general content of education does not precisely define the educational outcomes, which (although to a lesser extent than before) allows a variable approach to the implementation of courses in various accredited institutions.

Although the results of our own survey carried out in our mentor group were positive we feel there is a need for the continuous and systematic development of competencies, i.e. knowledge and skills of nurses who are mentoring students as a necessary and essential contribution to the quality of the educational process of our students. In this sense, we perceive the interdependence of educational outcomes, in both education and evaluation for more learners to permanently acquire the targeted complex knowledge and skills, as a necessary element for improving the work of not only the academic staff of our workplace, but also of the mentors of clinical nursing apprenticeships and the students themselves.

\section{References:}

1. ALLAIS S, RAFFE D, YOUNG M (2009) Researching NQFs: some conceptual issues (Geneva: International Labour Office - Skills and Employability Department, 2009).

2. AYFER E, HATICE Y S (2008) Students Opinions About and Expectations of Effective Nursing Clinical Mentors. Journal of Nursing Education. Thorofare: 2008, vol. 47, Iss 3, pg. 118, 6 pgs ISSN 01484834.

3. BERGAN S (2007) Qualifications. Introduction to a Concept (Strasbourg: Council of Europe, 2007).

4. HNILICA J, PABIAN P, HAJKOVA T (2012) National Qualification Framework for Tertiary Education in the Czech Republic. Volume 3, Experiences and Recommendations. 1st edition. Prague: Ministry of Education, Youth, and Sports, 2012. 98 s. ISBN 978-80-87601-11-2. CHAKROUN B (2010) „National Qualification Frameworks: from policy borrowing to policy learning “, European Journal of Education 45 (2010), n. 2, pgs. 199-216.

5. JIRKOVSKY D (2010) Self-evaluation results of selected pedagogical and managerial skills of nurses and mentors of clinical residencies. In: Marty Staňková's Work Day: Proceedings of the Conference with International Participation. 2009. 1st edition. Karolinum: Prague, 2010 s. $37-44$. ISBN 978-80-254-5597-5.

6. JIRKOVSKY D (2010) Supervision of Professional Residencies in a Certified Course for the Preparation of Mentors of Clinical Nursing Residencies and Trainers of Specialized Education. In. The Road to Professional Nursing: Proceedings of the Silesian Conference of Nursing with International Participation. Opava: Silesian University 
in Opava, 2010, s. 107 - 109 ISBN 978-807248-607-6.

7. JOWETT S (1994) Challenges and change in nurse education: a study of the implementation of Project. Great Britain: National Foundation for Educational Research in England and Wales, 1994. ISBN 0700513604 (v. 1) 0700513612 (v. 2).

8. MATULNIKOVA L (2009) A Mentor in Clinical Residencies. In: Botikova, A. et al. Manual for Mentors in Nursing. 1st edition. Trnava: TYPI UNIVERSITATIS TYRNAVIENSIS, 2009. 8 - 12 s. ISBN 978-808082-253-8.

9. MATULNIKOVA L (2009b) Nursing as a science. In: Botikova, A. et. al. Manual for mentors in nursing. $1^{\text {st }}$ edition. Trnava: TYPI UNIVERSITATIS TYRNAVIENSIS, 2009. Pgs. 13 - 58. ISBN 978-80-8082-2538.

10. PABIAN P (2012) How to Teach in Higher Education: A Research Approach to Learning. STUDY. In aula1/2012/XX, pgs. 48, 72.

11. PRUCHA J (1997) Modern pedagogy. $1^{\text {st }}$ edition: Prague, Portál, 1997, 495 s. ISBN 80-7178-170-3.

12. STRATEGIC DOCUMENTS FOR GENERAL NURSES AND MIDWIVES 2, $1^{\text {st }}$ edition, Prague, Ministry of Health of the Czech Republic, pg. 271, ISBN 80-8504721-7. 